\title{
Rapid detection of carbapenem resistance: targeting a zero level of inadequate empiric antibiotic exposure?
}

\author{
Andrea Cortegiani ${ }^{1 *} \mathbb{D}$, Vincenzo Russotto ${ }^{1}$, Pasquale lozzo ${ }^{2}$, Santi Maurizio Raineri ${ }^{1}$ and Antonino Giarratano ${ }^{1}$
}

Keywords: Multidrug-resistant bacteria, Carbapenem resistance, Polymerase chain reaction

Resistance to carbapenems is an increasingly encountered phenomenon in the ICU, complicating empiric and targeted antimicrobial therapy. Infections due to carbapenem-resistant microorganisms are characterized by high morbidity and mortality $[1,2]$. Recently, there has been an increasing interest in rapid detection techniques, based on real time on-demand easy-to-use PCR, to detect genes responsible for carbapenem resistance. One of these techniques is the Cepheid Xpert Carba- $R$ assay, which is able to detect and differentiate five of the most frequent genes associated with non-susceptibility to carbapenems in Gram-negative bacteria $\left(b l a_{K P C}, b l a_{V I M}\right.$, $\left.b l a_{O X A-48}, b l a_{I M P-1}, b l a_{N D M}\right)$. The diagnostic performance of this assay seems to be high when compared to classic microbiological cultures and gene identification with in-house PCR in a clinical setting, especially in intraabdominal infections using samples from rectum or abdominal drainage material [3, 4]. Originally, assays for screening of patients carrying multidrug-resistant organisms were used to guide infection control programs, to restrict access to patients' health-care zones, or for outbreak surveillance. However, several studies reported an association between detection from surveillance techniques and subsequent infection etiology, improving the rate of adequate empiric antimicrobial treatment [5].

The Xpert Carba- $\mathrm{R}$ assay delivers results in less than 1 hour. It might be argued that the identification of genes associated with non-susceptibility at the beginning of therapeutic decision-making, when clinicians are

\footnotetext{
*Correspondence: cortegiania@gmail.com

'Department of Biopathology and Medical Biotechnologies (DIBIMED),

Section of Anaesthesia, Analgesia, Intensive Care and Emergency, University

Hospital Paolo Giaccone, University of Palermo, Via del vespro 129, 90127

Palermo, Italy

Full list of author information is available at the end of the article
}

deciding whether to add carbapenems or not, may lower the rate of inadequate use of these antimicrobials, to which resistance rates are continuously increasing. This application would shift the utility of this technique from screening to an active part of therapeutic decisionmaking. To date, two aspects may limit its application. First, although it is able to detect five of the most common genes, clinicians should carefully evaluate which are the genetic determinants of carbapenem-resistance in their ICU to optimize diagnostic performance. Second, the data came from rectal swabs and material from abdominal drainage and the clinical usefulness in other clinical settings should be tested.

Following this road, we may hope to obtain, in the near future, information on genes associated with resistance to antibiotics by easy-to-use, on-demand techniques before starting therapies and reducing inadequate empiric treatment to nearly zero.

\section{Abbreviations \\ PCR: Polymerase chain reaction}

\section{Acknowledgements \\ None.}

\section{Funding}

The authors did not receive any funding for this article.

\section{Availability of data and material}

Not applicable.

\section{Authors' contributions}

$A C, V R, P I, S M R$, and AG conceived the content of the letter. AC and VR wrote the text. All authors read and approved the final version of the manuscript.

\section{Competing interests \\ The authors declare that they have no competing interests.}

\section{Consent for publication}

Not applicable. 


\section{Ethical approval and consent to participate}

Not applicable.

\section{Author details}

'Department of Biopathology and Medical Biotechnologies (DIBIMED), Section of Anaesthesia, Analgesia, Intensive Care and Emergency, University Hospital Paolo Giaccone, University of Palermo, Via del vespro 129, 90127 Palermo, Italy. ${ }^{2}$ Intensive Care Unit, University Hospital Paolo Giaccone, University of Palermo, Via del vespro 129, 90127 Palermo, Italy.

\section{Published online: 19 December 2016}

\section{References}

1. Karam G, Chastre J, Wilcox MH, Vincent J-L. Antibiotic strategies in the era of multidrug resistance. Crit Care. 2016:20:136.

2. Russotto V, Cortegiani A, Graziano G, Saporito L, Raineri SM, Mammina C, et al. Bloodstream infections in intensive care unit patients: distribution and antibiotic resistance of bacteria. Infect Drug Resist. 2015;8:287-96.

3. Tato M, Ruiz-Garbajosa P, Traczewski M, Dodgson A, McEwan A, Humphries $\mathrm{R}$, et al. Multisite evaluation of Cepheid Xpert Carba-R assay for detection of carbapenemase-producing organisms in rectal swabs. J Clin Microbiol. 2016:54:1814-9.

4. Cortegiani A, Russotto V, Graziano G, Geraci D, Saporito L, Cocorullo G, et al. Use of Cepheid Xpert Carba-R(R) for rapid detection of carbapenemaseproducing bacteria in abdominal septic patients admitted to intensive care unit. PLoS One. 2016;11:e0160643.

5. Papadomichelakis E, Kontopidou F, Antoniadou A, Poulakou G, Koratzanis E, Kopterides $\mathrm{P}$, et al. Screening for resistant gram-negative microorganisms to guide empiric therapy of subsequent infection. Intensive Care Med. 2008:34:2169-75. 